\title{
QUANTIFICAÇÃO E ANÁLISE DOS FATORES DE CRESCIMENTO IL-6, TGF-B, VEGF E B-FGF NO SOBRENADANTE DE CULTURA DE MIELOMA MULTIPLO. UMA CORRELAÇÃO COM O MICROAMBIENTE TUMORAL
}

\author{
QUANTIFICATION AND ANALYSIS OF GROWTH FACTORS IL-6, TGF-B, \\ VEGF AND FGF-B IN THE CULTURE SUPERNATANTS OF MULTIPLE \\ MYELOMA: A CORRELATION WITH THE TUMOR MICROENVIRONMENT
}

\author{
Milton Sérgio Bohatch Jr*; Paula Dayana Matkovski*; \\ Paula Josiane Janowski Trojan*; Giovani Marino Favero* \\ * Universidade Estadual de Ponta Grossa, Setor de Ciências Biológicas e da Saúde, \\ Laboratório Multidisciplinar de Pesquisas Básica e Aplicada a Biologia e Saúde. \\ E-mail: gmfavero@uepg.br
}

Recebido para publicação em 11/03/2010

Aceito para publicação em 04/05/2010

\begin{abstract}
RESUMO
O mieloma múltiplo (MM) é uma neoplasia monoclonal de plasmócitos, caracterizado pela proliferação excessiva de plasmócitos malignos na medula óssea ${ }^{1}$. No Mieloma, a medula óssea atua como o microambiente ideal para a sobrevivência e proliferação dos plasmócitos modificados. Dentro desse microambiente, há uma complexa rede de sinalização celular envolvendo várias citocinas, conferindo sobrevivência, desenvolvimento do tumor e resistência aos quimioterápicos. O propósito desse trabalho experimental foi investigar a secreção de citocinas (IL6, TGF-B, VEGF e B-FGF) em uma linhagem celular de MM (RPMI 8226). As células do MM foram cultivadas em frascos de cultura contendo meio RPMI 1640 suplementado com $10 \%$ de Soro Fetal Bovino (SFB) e mantidas em incubadora de tensão de $\mathrm{CO}_{2}$ a $5 \%$ e $37^{\circ} \mathrm{C}$. A quantificação de citocinas e fatores de crescimento presentes no sobrenadante da cultura celular de mieloma múltiplo foi realizada através do método de ELISA. As citocinas mensuradas no sobrenadante celular, em especial a IL-6 e o VEGF, relacionam-se diretamente com o microambiente tumoral, promovendo a angiogênese e ativando vias de sinalização anti-apoptóticas, o que confere às células de MM características de sobrevivência e proliferação.
\end{abstract}

Palavras-Chave: Mieloma múltiplo. Interleucina-6. VEGF. TGF-B. B-FGF.

\begin{abstract}
Multiple myeloma (MM) is a monoclonal neoplastic plasma cell characterized by the excessive proliferation of malignant plasma cells in the bone marrow. The bone marrow microenvironment is necessary for the survival and proliferation of MM cells. Within this microenvironment there is a complex cellular signaling involving multiple cytokines conferring survival, tumor development and resistance to chemotherapeutic agents. The purpose of this experimental work was to investigate
\end{abstract}


the secretion of cytokines (IL-6, TGF-B, VEGF and FGF-B) in a MM cell line (RPMI 8226). MM cells were cultured in culture flasks containing RPMI 1640 supplemented with $10 \%$ Fetal Bovine Serum (FBS) and kept in an incubator CO2 tension to $5 \%$ and $37^{\circ} \mathrm{C}$. Quantification of cytokines and growth factors present in the cell culture supernatant of multiple myeloma was performed using the ELISA method. Cytokines measured in cell supernatants, especially IL-6 and VEGF, relate directly to the tumor microenvironment, promoting angiogenesis and signaling pathways activating anti-apoptotic, which provide the MM cells the necessary characteristics to survive and proliferate.

Keywords: Multiple myeloma. IL-6. VEGF. TGF-B. B-FGF.

\section{Introdução}

O mieloma múltiplo (MM) é uma neoplasia monoclonal dos plasmócitos, caracterizado pela proliferação excessiva dos mesmos na medula óssea (HIDESHIMA et al, 2004). A medula óssea é o microambiente necessário para a sobrevivência e proliferação das células de MM. Dentro desse microambiente, há uma complexa rede de sinalização celular entre as células do $\mathrm{MM}$ e as células do estroma medular (CEM), envolvendo citocinas, receptores e moléculas de adesão. Essas interações conferem sobrevivência, desenvolvimento do tumor e resistência aos quimioterápicos (BOMMERT et al. 2006; KUEHL et al. 2002).

Vários estudos demonstraram o papel chave da interleucina-6 (IL-6) como o principal fator de crescimento e de sobrevivência para as células do MM (ANDERSON et al., 1989; KLEIN et al., 1989; KAWANO et al., 1988). Em circunstâncias normais, a IL-6 causa a diferenciação dos plasmócitos, enquanto que na patogênese do MM, ela causa proliferação e também inibe a apoptose das células cancerígenas (KLEIN et al, 1995; CHAUHAN, 1996). Há uma série de eventos dentro do microambiente tumoral que levam a secreção de IL-6. Algumas células de MM secretam IL-6 como fator de crescimento. Entretanto, são as CEM as maiores responsáveis pela secreção de IL-6 no microambiente tumoral. Tais células aumentam a secreção desta citocina em resposta à aderência das células de MM sobre as mesmas (CHAUHAN et al., 1996; UCHIYAMA et al., 1993). Há também um looping parácrino, no qual as células de MM secretam VEGF que estimula as CEM a secretarem mais IL-6 no microambiente (UCHIYAMA et al., 1993; DANKBAR et al., 2000).

Estudos recentes demonstraram o envolvimento da angiogênese na patogênese de várias neoplasias hematológicas, (RIBATTI et al., 1996; FIEDLER et al., 1997; AGUAYO et al., 2000) de modo que o aumento da densidade capilar esta relacionado com pior prognóstico (SEZER et al., 2000; RAJKUMAR et al., 2000). Foi também reportado que pacientes com MM apresentam altos níveis de citocinas angiogênicas (VEGF, bFGF e HGF) na medula óssea (RAIMONDO et al., 2000). A maioria das linhagens de MM secretam VEGF, enquanto que e as CEMs secretam tanto VEGF quanto bFGF, resultando em uma imbricada relação que aumenta a adesão das células de MM, além de promover angiogênese no microambiente tumoral (RIBATTI et al., 1996).

O fator de crescimento do endotélio vascular (VEGF) está presente durante toda a vida do tumor, sendo ele essencial e fator primário no desenvolvimento do mesmo. À medida que a massa tumoral multiplica-se são ativados fatores secundários relacionados com a angiogênese, como as citocinas e outros fatores de crescimento: fator de crescimento fibroblástico beta ( $\beta \mathrm{FGF}$ ) e fator transformador de crescimento beta (TGF $\beta$ ). Porém, o VEGF continua sendo o principal fator pró-angiogênico nos tumores (PEREIRA et al., 2008).

Este trabalho tem como objeto de estudo mensurar a quantidade de quatro importantes citocinas envolvidas na patogênese do MM (VEGF, bFGF, TGF-B e IL-6). Estas citocinas estão presentes no sobrenadante da linhagem celular de MM - RPMI 8226. 


\section{Materias e métodos}

\section{Cultivo Celular}

A linhagem RPMI 8226 é uma linhagem de MM humana, oriunda de sangue periférico e foi estabelecida em 16/06/1966 por Moore e Kitamura no Roswell Park Memorial Institute (MOORE et al., 1968). Trata-se da linhagem de MM mais bem documentada e com considerável estabilidade genética. Tem características fenotípicas de células linfoplasmocitárias, com alto gral de anaplasia e apresenta um tempo de dobramento de 40-80 horas. Diferente de outras linhagens de MM, esta linhagem ocorreu espontaneamente sem a infecção in vitro pelo vírus do Epstein-Barr (KLEIN et al.,1987; MINOWADA et al, 1974). As células de MM (RPMI 8226) foram doadas pelo Prof. Dr. Sérgio Paulo Bydlowski da Faculdade de Medicina da USP.

As células foram cultivadas em frascos próprios de cultura, utilizando meio RPMI 1640 suplementado com $10 \%$ de soro fetal bovino (SFB), e mantidas em incubadora a $37^{\circ} \mathrm{C}$ de atmosfera úmida com $5 \%$ de $\mathrm{CO}_{2}$ até confluência (FRESHNEY, 1994). O sobrenadante foi coletado e armazenado em freezer $\left(-4^{\circ} \mathrm{C}\right)$.

\section{Quantificação das Citocinas}

A quantificação das citocinas e dos fatores de crescimento presentes no sobrenadante de MM foi realizada através do método de ELISA (Enzyme Linked Immuno Sorbent Assay), por leitora ELISA (Lab Life MXPN 2001) na faixa de $450 / 690 \mathrm{~nm}$. O VEGF e o $\beta$-FGF foram quantificados utilizando-se kit RayBio ${ }^{\circledR}$, enquanto a IL-6 e o TGF- $\beta$ foram quantificados utilizando-se kit eBioscience ${ }^{\circledR}$, segundo a metodologia descrita pelos fabricantes.

\section{Resultados}

Quantificação dos fatores de crescimento e citocinas

De acordo com a metodologia descrita pelo fabricante, realizou-se a média dos valores obtidos nas quatro medições, de cada fator e citocina de crescimento presentes no sobrenadante de mieloma múltiplo, obtendo-se o valor da absorbância. Foram realizados os cálculos dos valores das concentrações em pg/mL (Tabela 1). Com o resultado da média dos valores, pode-se verificar a presença de quantidades significativas de fatores de crescimento e citocinas.

Tabela 1 - Quantificação das citocinas presentes no sobrenadante de cultura de mieloma múltiplo imortalizada independente de IL-6.

\begin{tabular}{ccc}
\multicolumn{3}{c}{$\mathrm{nm}}$. \\
\hline Fatores de Crescimento & Média $(\mathbf{p g} / \mathbf{m L})$ & Desvio Padrão \\
\hline VEGF & 247,3 & $\pm 3,296$ \\
IL-6 & 8033,3 & $\pm 8,963$ \\
TFG- $\boldsymbol{\beta}$ & 19,8118 & $\pm 5,80917$ \\
FGF & 9,8333 & $\pm 0,3512$ \\
\hline
\end{tabular}

\section{Discussão}

Vários fatores e citocinas compõem o microambiente da medula-óssea, sendo essenciais para o desenvolvimento e sobrevivência do MM. Busca-se uma maior compreensão dos fatores desse microambiente para eleger novos alvos que possam ser utilizados em terapias mais eficazes. Os fatores de crescimento e a citocina mensurados no presente artigo, estão estreitamente envolvidos na sinalização celular que estimula o crescimento e inibe a apoptose das células neoplásicas, bem como promove a angiogênese.

A citocina presente no sobrenadante (interleucina-6) liga-se a proteínas transmembrana (gp130) presentes na superfície de algumas células, desencadeando a ativação da via $\mathrm{PI} 3 \mathrm{~K} / \mathrm{mTOR} / \mathrm{p} 70 \mathrm{~S} 6 \mathrm{~K}$ que resulta na angiogênese, além de ter ação direta sobre os inibidores das proteínas reguladoras do ciclo celular, inibindo os sinais pró-apoptóticos. A IL-6 também age induzindo sinais anti-apoptose, através da transcrição aumentada do gene Bcl2 (função anti-apoptótica) e inibidores de caspase (ISHIKAWA et al., 2006). Essa sinalização também promove a secreção autócrina de VEGF pelos plasmócitos, que regula a produção de citocinas e a expressão das moléculas de adesão (UCHIYAMA et al., 1992).

As células do estroma da medula óssea fornecem apoio eficaz para a sobrevivência e pro- 
liferação das células do mieloma múltiplo, produzindo um elevado nível de interleucina IL-6 (ANDERSON et al., 1989). Através da interação com CEM, as células do mieloma também produzem de citocinas que estimulam a osteoclastogênese e a angiogênese (KLEIN et al., 1989).

O aumento da densidade microvascular na medula óssea em conseqüência da angiogênese é induzido pelo VEGF secretado pelas células do mieloma e do estroma medular. Essa produção de VEGF decorre do estímulo direto da IL-6 produzida pelas células do microambiente, o que proporciona a sobrevida dos plasmócitos neoplásicos (UCHIYAMA et al., 1992). Aliado a isso, as células tumorais têm desenvolvido uma variedade de mecanismos para evitar a resposta imune. Um destes mecanismos envolve a inibição de células dendríticas (células apresentadoras de antígenos) que estimulam as células $B$ e células $T$. $O$ fator de crescimento do endotélio vascular (VEGF) pode impedir a maturação funcional das células dendríticas a partir de seus progenitores hematopoiéticos. Dessa maneira, a secreção de VEGF pelo tumor pode desempenhar um importante papel na supressão da resposta imunológica antitumoral. Outro mecanismo inclui o TGF $\beta$, que elimina as células $\mathrm{B}$ e T através da inibição da via de sinalização autócrina de interleucina-2 (IL-2) (URASHIMA et al., 1996).

A elucidação dos fatores de crescimento que integram o microambiente tumoral pode gerar promissores alvos terapêuticos para intervenções mais efetivas na remissão do processo neoplásico, através da inibição direta ou indireta desses fatores e citocinas. O presente artigo demonstrou que várias citocinas importantes na patogênese são secretadas pelas próprias células do MM, levando a uma retro-alimentação positiva para a expansão tumoral e para a angiogênese, e possivelmente, a uma maior tolerância a apoptose. Justifica-se, dessa forma, o comportamento agressivo, as características de resistência à quimioterapia e o alto potencial de letalidade relacionado ao MM.

Auxilio Financeiro: Fundação Araucária e CNPq.

\section{REFERÊNCIAS}

AGUAYO, A., KANTARJIAN, H., MANSOURI, T., GIDEL, C., ESTEY, E., THOMAS, D., KOLLER, C., ESTROV, Z.; O'BRIEN, S.; KEATING, M., FREIREICH, E., ALBITAR M. Angiogenesis in acute and chronic leukemias and myelodysplastic syndromes. Blood., v.96, p.2240-2245, 2000.

ANDERSON, K. C.; JONES, R. M.; MORIMOTO, C.; LAEVITT, P.; BARUT, B. A. Response pattern of purified myeloma cells to hematopoietic growth factors. Blood, v.73, p.1915-1924, 1989.

BOMMERT, K.; BARGOU, R. C.; STÜHMER, T.; Signalling and survival pathways in multiple myeloma. Eur J Cancer, v.42, p.1574-1580, 2006.

CHAUHAN, D.; UCHIYAMA, H.; AKBARALI, Y., et al. Multiple myeloma cell adhe- sion-induced interleukin-6 expression in bone marrow stromal cells involves activation of NF-kappaB. Blood, v.87, p.1104-1112, 1996.

CHAUHAN, D.; UCHIYAMA, H.; AKBARALI, Y., URASHIMA, M.; YAMAMOTO, K.; LIBERMANN, T. A.; ANDERSON, K. C. Multiple myeloma cell adhesion- induced interleukin-6 expression in bone marrow stromal cells involves activation of NF-kappa B. Blood; v.87, p.1104-1112, 1996.

DANKBAR, B.; PADRÓ, T.; LEO, R., et al. Vascular endothelial growth factor and iterleukin-6 in paracrine tumorstromal cell interactions in multiple mieloma. Blood, v.95, p.2630-2636, 2000.

FIEDLER, W.; GRAEVEN, U.; ERGUN, S.; VERAGO, S.; KILIC, N, STOCKSCHLADER, M.; HOSSFELD, Dk. Vascular endothelial growth factor, a possible paracrine growth factor in human acute myeloid leukemia. Blood; v.89: 1870-1875, 1997.

FRESHNEY R. I.. Culture of animals cells: a manual of basic technique. 3 ed. New York, Welly-Liss, 1994.

HIDESHIMA, T., BERGSAGEL, P.L., KUEHL, W. M.; ANDERSON, K. C. Advances in biology of multiple myeloma: clinical applications. Blood, v.104, p.607-618, 2004.

ISHIKAWA, H.; TSUYAMA, N.; OBATA, M.; KAWANO, M. M.. Mitogenic signals initiated via inteleukin-6 receptor complexes in corporation with other transmembrane molecules in myelomas. J. Clin. Exp. Hematopathol.;: v.46, p.55-66, 2006.

KAWANO, M.; HIRANO, T.; MATSUDA, T.; TAGA,T.; HORII, Y.; IWATO, K.; ASAOKU, H.; TANG, B.; TANABE, O.; TANAKA, H. Autocrine generation and essen- tial requirement of BSF-2/IL-6 for human multiple myeloma. Nature, v.332, p.83-85, 1988.

KLEIN, B.; ZHANG, X. G.; JOURDAN, M.; CONTENT, J.; HOUSSIAU, F.; AARDEN, L.; PIECHACZYK, M.; 
BATAILLE, R. Paracrine rather than autocrine regu- lation of myeloma-cell growth and differentiation by interleukin- 6 . Blood; v.73, p.517-526, 1989.

; ZHANG, X. G.; LU, Z. Y., et al. Interleukin-6 in human multiple myelo-ma. Blood., v.85, p.863-572, 1995.

.; JOURDAN, M.; VAZQUEZ, A. et al. Production of growth factors by human Myeloma cells. Cancer Research, v.47, p.4856-4860, 1987.

KUEHL, W. M.; BERGSAGEL, P. L. Multiple myeloma: evolving genetic events and host interactions. In Situ., v.2, March, 2002.

MINOWADA, J.; NONOYAMA, M.; MOORE, G. E. et al. The Presence of the Epstein-Barr viral genome in human Lymphoblastoid B-Cell Lines and Its Absence in a Myeloma Cell Line1. Cancer Research, v.34, p.1898-1903, 1974.

MOORE, G. E.; KITAMURA, H. Cell line derived from patient with myeloma. New York State Journal of Medicine; v.68, n.15, p.2054-2060, 1968.

PEREIRA J,; PEDROSO-MEIRELES, A. N. L., GODOY, C. R.T.; CHAMONE, D. A. F . Papel da Célula Endotelial em Neoplasias Malignas Hematológicas. Rev. Bras. Hematol. Hemoter, v.30, n.3, p.223-228, 2008.

RAIMONDO, F. D; AZZARO, M. P.; PALUMBO, G. A.; BAGNATO, S. GIUSTOLISI G.; FLORIDIA, P. M., SORTINO, G.; GIUSTOLISI, R. Angiogenic factors in multiple myeloma: higher levels in bone marrow than in peripheral blood. Haematologica, v.85, p.800-805, 2000.

RAJKUMAR, S. V.; LEONG T.; ROCHE P.C.; et al. Prognostic value of bone marrow angiogenesis in multiple myeloma. Clin Cancer Res., v.6, p.3111-16, 2000.

RIBATTI, D.; VACCA, R. D., NICO, B., FANELLI, M.; RONCAL, L.; DAMMACCO, F. Angiogenesis spectrum in the stroma of B-cell non-Hodgkin's lymphoma. An immunohistochemical and ultrastructural study. Eur J Haematol; v.56, p.45-53, 1996.

SEZER, O.; NIEMOLLER, K.; EUCHER, J. et al. Bone marrow microvessel density is a prognostic factor for survival in patients with multiple myeloma. Ann Hematol., v.79, p.574-577, 2000.

UCHIYAMA, H.; BARUT, B. A.; CHAUHAN, D.; CANNISTRA, S. A.; ANDERSON K. C. Characterization of adhesion molecules on human myeloma cell lines. Blood, v.80, p. 2306-2314, 1992.

.; BARUT, B.A.; MOHRBACHER, A. F.; CHAUHAN, D.; ANDERSON, K. C. Adhesion of human myeloma derived cell lines to bone mar- row stromal cells stimulates interleukin-6 secretion. Blood, v.82, p.3712- 3720, 1993.

URASHIMA, M.; OGATA, A.; CHAUHAN, D.; HATZIYANNI, M.; VIDRIALES, M. B.; DEDERA, D. A. et al. Transforming growth factor-beta1: differential effects on multiple myeloma versus normal B cells. Blood; v.87, p.1928-1938, 1996. 